\title{
A TEORIA DO CAPITAL HUMANO E A NOÇÃO DE EMPREGABILIDADE: UM ESTUDO COMPARATIVO.
}

\author{
Janilson Gomes da Fonseca*, Maria Aparecida Dos Santos Ferreira \\ ${ }^{\star} E$-mail: janilson.g.fonseca@gmail.com \\ Instituto de Educação, Ciência e Tecnologia do Rio Grande do Norte \\ DOI: $10.15628 /$ rbept.2020.7859
}

Artigo submetido em: out/2018 e aceito em mar/2020

\begin{abstract}
RESUMO
Este artigo propõe refletir acerca da teoria do capital humano emergida na década de 70 do século passado e cotejá-la com a noção de empregabilidade dos dias atuais. A primeira concebida sob o ideário liberal e a segunda sob o do neoliberalismo, respectivamente. Trata-se de pesquisa exploratória, qualitativa e descritiva. Tem como referencial teórico a abordagem sócio crítica da realidade e como fio condutor a dialética. A metodologia utilizada foi revisão bibliográfica em alguns autores pesquisadores da temática. Os resultados alcançados foram que a noção de empregabilidade é a face moderna da teoria do capital humano. Ambas, se apresentam em períodos históricos distintos, porém, com uma mesma ideologia: a educação e a qualificação profissional garantidora de inserção e/ou permanência no mundo do trabalho.
\end{abstract}

Palavras-chave: Teoria do capital humano. Empregabilidade. Neoliberalismo. Ideologia.

\section{THE THEORY OF HUMAN CAPITAL AND THE NOTION OF EMPLOYABILITY: A COMPARATIVE STUDY.}

\begin{abstract}
This article proposes to reflect on the theory of human capital emerged in the 1970s from last century and to compare it with the notion of employability of the present day. The first was conceived under the liberal ideology and the second under that of neoliberalism, respectively. It is an exploratory, qualitative and descriptive research. It has as theoretical reference the sociocritical approach of reality and as a guiding thread the dialectic. The methodology used was a bibliographic review in some authors of the subject. The results achieved were that the notion of employability is the modern face of human capital theory. Both are presented in distinct historical periods, but with the same ideology: education and professional qualification guaranteeing insertion and / or permanence in the world of work.
\end{abstract}

Keywords: Theory of human capital. Employability. Neoliberalism. Ideology. 


\section{INTRODUÇÃO}

Este artigo consiste em um recorte de dissertação de mestrado, apresentada ao programa de pós-graduação em educação profissional PPGEP do Instituto Federal de Educação, Ciências e Tecnologia do Rio Grande do Norte - IFRN, cujo escopo, discutiu a noção de empregabilidade nas políticas públicas de educação profissional desde os anos de 1990 do século passado no Brasil, as quais seguiram tendências em conformidade com o ideário neoliberalista.

A partir da década de 90 do século XX, sob o governo de Fernando Henrique Cardoso, (1995-2002) o Brasil experimentava uma mudança de paradigma no regime capitalista de acumulação do capital. Tratava-se do advento do regime neoliberal ${ }^{1}$, da reforma de administração do Estado, da descentralização das políticas públicas, da restruturação produtiva ${ }^{2}$ do capital e de privatizações e parcerias com o setor privado. Com essa mudança do regime de acumulação de modo capitalista Taylorista/Fordista ${ }^{3}$ para 0 de acumulação flexível, a educação de um modo geral, seguindo essa lógica de mudança na estrutura do Estado, teve que adaptar-se a essa nova realidade para atender a novas demandas do mundo do trabalho, sofrendo influências diretas na educação em geral e na qualificação profissional em particular. Sendo assim, o trabalhador/a passou da condição de especialista (orientado para executar uma só função ou tarefa) para uma formação polivalente.

Todas essas mudanças ocasionadas por esse novo modelo de acumulação do capital e no mundo do trabalho, caracterizam-se basicamente pela diminuição dos ciclos de produção, mudanças na divisão do trabalho dentro das empresas, consolidação das tecnologias da computação e da informática, polivalência e treinamento dos trabalhadores como requisitos essenciais aos novos processos produtivos. ANTUNES (1997)

\footnotetext{
${ }^{1}$ As ideias neoliberais foram geradas nos países ricos, onde foram objeto de estudo e implementação desde o final dos anos 1970, com base nos estudos do grupo que se reuniu em Mont Pelerin, Suíça, em 1974, por convocação do economista Frieedrich Hayek, para preservar os princípios e valores do liberalismo. (CIAVATTA, 2016).

${ }^{2}$ Entende-se por restruturação produtiva do capital, nesse contexto, também como toyotismo ou modelo de acumulação toyotista. Segundo Alves, o novo complexo de reestruturação produtiva trata de inovações sociais interiores e exteriores à produção capitalista. Nas inovações interiores, destaca-se as inovações organizacionais; as tecnológicas e as sócio metabólicas. Nas inovações exteriores, são as econômicas e geo - econômicas, as políticos institucionais, e as inovações culturais. ( ALVES,2007.p.155)

${ }^{3}$ Para Harvey, a data oficial simbólica do Taylorismo Fordismo, ocorreu em 1914, quando Henry Ford introduziu seu dia de oito horas e cinco dólares como recompensa para os trabalhadores da linha de montagem de automóveis [...] aliado com a contribuição de F.W.Taylor, com os princípios da administração cientifica, publicado em 1911, um influente tratado que descrevia como a produtividade poderia ser radicalmente aumentada por meio da decomposição de tarefas, seguindo padrões rigorosos de tempo e estudo de movimentos [...].(HARVEY,1993,p.120).
} 
Nesse cenário, verificou-se a diminuição e o desaparecimento de muitos postos de trabalho que outrora existia, o que intensificou a concorrência e a competitividade entre os trabalhadores/as.

Assim sendo, o sistema neoliberal de produção, teve que se adaptar visando ao controle social por meio de novas ideologias mascaradoras da realidade que se anunciava em razão de mais escassez de postos de trabalho e, por extensão, de desempregos e precarização do trabalho e do trabalhador/a.

Pois, é nesse contexto de mudanças, que emerge a noção de empregabilidade, reprodução ideológica, com uma nova roupagem da teoria do capital humano, que foi idealizada na "fase de ouro" do capitalismo moderno no pós-segunda guerra mundial, nos países capitalistas centrais. ALVES (2007).

Nesse sentido, conforme Alves (2007) para se apreender o significado essencial dos mais diversos processos sociais, mormente os vinculados às novas ideologias da Educação Profissional, com foco nas novas qualificações e na noção de empregabilidade, parte-se da totalidade concreta do momento atual de desenvolvimento do sistema de controle sócio - metabólico do capital.

Destarte, essa pesquisa busca refletir acerca da teoria do capital humano emergida na década de 70 do século $X X$ e confrontá-la com a noção de empregabilidade dos dias atuais. A primeira concebida sob o ideário liberal e a segunda sob o do neoliberalismo, respectivamente. Ambas, apresentam-se em períodos históricos distintos, porém, com uma mesma ideologia: a educação e a qualificação profissional garantidoras de inserção e/ou permanência no mundo do trabalho. Este, em conformidade com a lógica capitalista, transformou-se, em uma relação desigual e antagônica entre o trabalho e o capital em mais uma mercadoria e, denominado, mercado de trabalho.

Visto isso, buscar-se-á a compreensão de ideologia que está subjacente nas duas concepções, considerando que as ideias dominantes de uma época são as ideias da classe dominante, tanto materialmente como politicamente.

De acordo com Marx e Engels (1987):

As ideias da classe dominante são, em todas as épocas, as ideias dominantes, ou seja, a classe que é o poder material dominante da sociedade é, ao mesmo tempo, o seu poder espiritual dominante [...] os indivíduos que constituem a classe dominante também tem, entre outras coisas, consciência, e daí que pensem; na medida, portanto, em que dominam como classe e determina todo o conteúdo de uma época histórica, é evidente que o fazem em toda sua extensão e, portanto, entre outras coisas dominam também como pensadores, como produtores de ideias, regulam a produção e a distribuição de ideias do seu tempo; que, portanto, as suas ideias são as ideias dominantes da época. (MARX; ENGELS. 1987 p.72). 
Sobre esse excerto de concepção Marxiana, Chauí (1980, p.21), esclarece que Ideologia é:

\begin{abstract}
Uma falsa consciência da realidade. Essas ideias e representações tenderão a esconder dos homens o modo real como suas relações sociais foram produzidas e a origem das formas sociais de exploração econômica e de dominação política. [...] por seu intermédio, os homens legitimam as condições sociais de exploração e de dominação, fazendo com que apareçam verdadeiras e justas.
\end{abstract}

Nessa perspectiva, a ideologia na sociedade capitalista se exprime presumindo a execução de um discurso homogêneo, linear, universal, visando identificar a realidade social como a que as classes dominantes pensam e agem sobre ela, assim, escondem as contradições que há na essência, sobretudo, as referentes ao antagonismo entre capital e trabalho. Além disso, intimidam outros discursos e representações opostos. Nesse sentido, as desigualdades sociais e econômicas são escamoteadas da forma como foram produzidas, em uma relação desigual e de exploração do sistema produtivo sobre o trabalho humano. Ademais, a ideia que o trabalhador/a agora é responsável pela sua "empregabilidade", é difundida e veiculada ideologicamente como verdade inconteste em um cenário de postos de trabalho cada vez mais escassos.

A teoria do capital humano e a noção de empregabilidade, portanto, aqui comparadas, nada mais são do que uma das formas de manifestação desse poder ideológico da classe dominante. Assuntos que serão discutidos a seguir.

\title{
2. A TEORIA DO CAPITAL HUMANO
}

Theodore William Schultz (1902-1998), economista e ganhador do prêmio Nobel de Economia em 1976, analisou que muitas pessoas nos Estados Unidos da América passaram a investir fortemente nas suas formações e que esses investimentos influenciavam sobre o crescimento econômico. Para esse autor, o outro fator constitutivo do capital humano era o investimento em saúde e pesquisa. Ademais, objetivava mostrar que os países em desenvolvimento como o Japão, que fora parcialmente destruído na segunda grande guerra, por meio dessa teoria, conseguiu reconstruir sua economia em pouco tempo.

Schultz (1973), na obra, "o Capital Humano: investimento em educação e pesquisa" defendia que 0 investimento na capacidade humana poderia implicar no desenvolvimento no campo econômico e na competição entre os países capitalistas. 
A tese central de Schultz (1973) era que a concepção econômica teria negligenciado as duas classes de investimentos que eram de capital importância naquelas circunstâncias. Para ele, são elas: "O investimento no homem e na pesquisa, tanto no plano privado quanto no plano público. $O$ problema central desse estudo é o de esclarecer a natureza e os objetivos dessas duas atividades". (1973, p.15). Esse investimento, que sugere o autor, seria na educação formal pública ou privada.

De acordo com Alves (2007), a Teoria do Capital Humano foi construída na "idade de ouro" do capitalismo moderno do pós-segunda grande guerra mundial, nos países capitalistas centrais, por meio de uma perspectiva de integração de homens e mulheres ao mercado de trabalho e de consumo que seria capaz de se desenvolver um novo espírito de comunidade sob a égide da burocracia pública do Estado de bem-estar social ou Estado de providência, sob a predominância das políticas Keynesiana de bem-estar social e de pleno emprego.

No entanto, o conceito de capital humano para Frigotto (1993), pela extensão, recursos humanos, em uma ótica macroeconômica, o investimento no "fator humano" significará um dos determinantes basilares para o aumento da produtividade e fator de superação do atraso econômico e, do ponto de vista microeconômico, consiste no fator explicativo das diferenças individuais de produtividade e de renda e, consequentemente, de mobilidade social.

Mas para Schultz (1973),

O componente da produção, decorrente da instrução, é um investimento em habilidades e conhecimentos que aumenta futuras rendas e, desse modo, assemelha-se a um investimento em (outros) bens de produção. (1973, p. 33).

Com isso, Schultz (1973) e seus seguidores pretendiam, à época da criação do conceito, complementar os elementos que explicavam 0 crescimento econômico na concepção liberal, a alta de salários do fator trabalho nos países desenvolvidos e também explicar no âmbito individual, as diferenças nas rendas dos trabalhadores. Passou-se a postular que se deveria privilegiar e investir mais em "capital humano" do que em recursos físicos para a consecução de maiores rendas para a nação.

Com essa ideia, acreditava-se fortemente que essa teoria relacionava o crescimento econômico e o aumento da renda dos indivíduos ao grau de escolarização via escola pública ou privada. Defendia-se também que o investimento na educação é fundamental para desenvolver o capital humano. É por meio do processo educativo que produzirá algumas atitudes e conhecimentos para capacitar para o trabalho.

Entretanto, para Alves (2007), a promessa de integrar sistematicamente a escola pública como instância educativa das massas. Esse modelo de escola tornou-se uma instituição central de proporcionar condições que deveriam 
permitir a integração dos indivíduos rumo à cidadania. Com isso, sedimentouse a função simbólica da escola e da formação profissional para o mundo do trabalho. A partir da ideia de modernização, "criou-se um senso comum que articulava trabalho, educação, emprego e individualidade. A escola e as políticas educacionais podiam e deviam ser um mecanismo de integração dos indivíduos à vida produtiva". (ALVES, 2007, p. 252).

Conforme Schultz (1973), "ao investirem em si mesmas, as pessoas podem ampliar o raio de escolha posto a disposição. Esta é uma das maneiras por que os homens livres podem aumentar o seu bem-estar" (1973, p.33). Este investimento, para o autor, pode aumentar os ganhos produtivos do trabalhador, no campo econômicos e social.

Todavia, para Frigotto (2006), essa teoria que fora produzida pelos intelectuais da burguesia mundial, com essa noção, buscava-se explicar as desigualdades entre as nações e entre os indivíduos ou grupos sociais, escamoteando os reais fatores geradores de desigualdades e pobreza, a saber: a detenção em massa da propriedade privada dos meios de produção pela classe capitalista ou burguesia e, em uma relação desigual, do outro lado, a compra da única mercadoria que a classe trabalhadora dispõe para proverem sua subsistência e de seus parentes, a venda de sua força de trabalho.

Frigotto (1993) reforça que a educação não passa apenas conhecimentos para o mercado, mas também articula e desarticula outros saberes para os interesses dominantes prevalecerem. E completa que, "a escola é uma instituição social que mediante suas práticas no campo do conhecimento, valores, atitudes e, mesmo, por sua desqualificação, articula determinados interesses e desarticula outros" (1993, p. 44).

Entretanto, essa teoria não se sustenta porque não leva em conta uma sociedade dividida em classe e estruturalmente desigual. Para o autor, a teoria do capital humano representa a forma pela qual a visão burguesa reduz a prática educacional a um "fator de produção", a uma questão técnica.

Assim, por meio dessa teoria, produz-se a crença que o progresso técnico não apenas gera novos empregos, e sim, exige-se uma qualificação cada vez mais avançada. Do outro lado, a ênfase na crença que a aquisição de capital humano por via da escolarização e níveis mais altos de ensino, constitui-se em garantia de consecução e ascensão a um trabalho qualificado e, por conseguinte, a níveis de renda cada vez mais altos. (FRIGOTTO, 1993)

Com base nesses pressupostos, infere-se que a Teoria do Capital Humano contempla os investimentos na área educacional como forma de inserção e/ou retorno ao trabalho e ao capital e com isso, produzir uma transformação social. No entanto, as questões relacionadas com 0 antagonismo de classes são ignoradas. Pois, quem não conseguiu melhores posições na sociedade e no chamado mercado de trabalho, deve ser autoresponsabilizado pelo seu fracasso, porque não teve mérito suficiente para tal realização. 
No que diz respeito a isso, Frigotto (1993) completa que,

O investimento no "fator humano" passa a significar um dos determinantes básicos para 0 aumento da produtividade e elemento de superação do atraso econômico. Do ponto de vista macroeconômico, constitui-se no fator explicativo das diferenças individuais de produtividade $e$ de renda $e$, consequentemente, de mobilidade social. (FRIGOTTO, 1993, p.41. Grifos do autor).

Nesse sentido, o autor reforça a crítica que é evidente a limitação dessa teoria, uma vez que, ao contrário a tendência universal do aumento da escolaridade, o que ocorre, contrariamente, é o recrudescimento do emprego estrutural, precarização do trabalho, traduzidos no aumento explosivo da informalidade laboral, terceirizações etc., com perdas de direitos trabalhistas, sobretudo, nos países em desenvolvimento como o Brasil.

Trata-se de subordinar a função social da educação de maneira controlada para responder as demandas imediatas do capital. A educação se apresenta com um papel estratégico no contexto neoliberal, formar 0 trabalhador para o processo de produção no âmbito de sua execução. Dessa forma, para Frigotto (1993) "a educação dos diferentes grupos sociais de trabalhadores deve dar-se a fim de habilitá-los técnica, social e ideologicamente para o trabalho" (1993p. 26).

Enquanto para Kuenzer (1997), a educação no sistema regular de ensino, evidencia um objetivo claro, que é a de preparação dos pobres para atuarem no sistema de produção nos níveis de funções inferiores. O que ocorre na escola não é o processo de produção e reprodução do conhecimento para esta, mas uma transmissão de conhecimentos superficiais e desprovidos de criticidade que formam o estudante com habilidades e atitudes flexíveis que é facilmente mudado e/ou substituído na dinâmica do mercado de trabalho. A autora completa que essa forma de preparar o trabalhador, vai ao encontro da teoria do capital humano que defende que a educação é um fator predominante em direção à produtividade e para o equilíbrio das desigualdades sociais.

Dessa maneira, para autora,

a desigualdade entre os países não é uma questão estrutural, decorrente das relações imperialistas, mas uma questão conjuntural que poderá ser resolvida com o tempo, através de estratégias adequadas, como a formação de recursos humanos e o intervencionismo do Estado no planejamento da educação (KUENZER, 1997, p. 59).

A finalidade da educação nesse sentido é desqualificar a classe trabalhadora e desapropriá-la do saber do seu trabalho. Esses vínculos visa a 
atender as demandas do capital, transformando a escola em uma instituição funcional a classe burguesa, tornando-a desqualificada.

Reforça ainda que:

A distribuição do saber é produzida socialmente, e segundo as necessidades do capital, o que permite entender que a sua não democratização expressa pelo seu caráter seletivo e excludente não é uma disfunção, mas a sua própria forma de articulação com o capital. (KUENZER, 1997, p.22).

Desta feita, a escola se torna uma instituição de formação em que se prevalecem as relações de produção e o papel da escola de produzir certas atitudes e valores nos estudantes, não se tornam essencial e específico da prática educativa, mas sim, uma prática mediadora que satisfaça aos interesses do capital.

Com relação ao discurso que vincula à qualificação profissional a "empregabilidade", Silva (2015), com base nos escritos de Ramos (2006), mostra que com o agravamento da desigualdade no capitalismo atual, a noção de "capital humano" vem sendo redefinida pelas noções de sociedade do conhecimento, qualidade total, pedagogia das competências e empregabilidade. Essas noções, de acordo com a autora, acabam por atribuir aos membros da classe trabalhadora, a liberdade de sua escolha individual, a responsabilidade por seu desemprego ou subemprego.

Silva (2015) ressalta ainda que, ideologicamente, a teoria do capital humano, por exemplo, explícita no Programa Nacional de Acesso ao Ensino Técnico e Emprego (PRONATEC), carrega a intenção de fazer com que acreditem que estão sendo criadas condições de igualdade de acesso a empregos por meio do programa. Por outro lado, completa a autora que, "essa mesma crença propaga se não houver a inserção no mercado de trabalho é em razão das seleções que só absorvem os 'melhores profissionais', ou seja, a responsabilidade recai sobre os próprios sujeitos individualmente" (2015, p.125).

Destarte, implica dizer que o estado capitalista neoliberal se legitima como um suposto garantidor dos interesses gerais, no entanto, isenta-se de suas responsabilidades de promover condições reais e materiais por meio de políticas sociais destinadas a fomentar e/ou criar postos de trabalho que absorvam parte desse contingente exacerbado de desempregados e desocupados em todo o país. Nesse sentido, o discurso que liga a educação ao crescimento econômico liga-se também ao de Qualificação Profissional e ao da "empregabilidade". 


\section{A NOÇÃo DE EMPREGABILIDADE EM TEMPOS DE IDEÁRIO NEOLIBERAIS}

A noção de "empregabilidade" está em evidência na área acadêmica, no mundo empresarial e na discussão sobre políticas públicas no Brasil e em outros países. Todavia, ressalta-se que sua emergência é relativamente recente, em meados dos anos 90 do século passado. E reflexo do acirramento da crise pela qual passa o mercado da força de trabalho em tempos de reestruturação produtiva.

Para Guerra (2012), a questão da empregabilidade passou a ocupar um lugar de destaque no debate internacional a partir dos anos 1980 e, no Brasil, no início dos anos 1990, em razão das várias mudanças no mercado da força de trabalho que foram ocasionadas, principalmente, pela globalização da produção e pelo avanço e a emergência de novas tecnologias.

Segundo a autora, com base nos estudos de Gazier (2001),

há duas concepções a respeito de empregabilidade: a empresarial individual - que é a empregabilidade como a capacidade de adaptação da mão de obra diante das novas exigências do mercado de trabalho; e a crítico social que trata a empregabilidade como um discurso que transfere a responsabilidade pelo emprego, que deveria ser também da sociedade e do Estado, para o próprio trabalhador (GUERRA, 2012, p. 158 ).

Apesar de a primeira concepção predominar no imaginário popular, para efeito desse texto, utilizar-se-á a crítico social, consoante a consistência dos argumentos dos autores apresentados na sequência do texto. Concernente à crítica a essa noção e, subjacente às reflexões apresentadas, faz-se uso da dialética como fio condutor nas análises aqui propostas.

Fazendo parte do ideário neoliberal e inserida na reestruturação produtiva do capital ou na acumulação flexível, a noção que se apresentou central é o de empregabilidade. Esta consiste no pensamento de que cabe ao trabalhador se qualificar o quanto pode para se tornar empregável para uma quantidade diversa de postos de trabalho.

Nesse sentido, para Ferreira (2006):

O trabalhador precisa manter-se competitivo no mercado de trabalho; por isso, deve se preocupar em fazer cursos complementares à educação básica, de forma continuada para sua qualificação e atualização. Por isso também deve adquirir as competências necessárias para driblar um contexto bem mais excludente. O simbolismo que vem carregado na noção de competência intenta fazer do trabalhador um sujeito nãoreagente, portanto disciplinado frente às exigências do 
mercado de trabalho. Esse é um aspecto importante para a análise da educação profissional no País. (Ferreira, 2006, p.16).

Em outros termos, a noção de empregabilidade transfere a responsabilidade do desemprego, da desocupação e não inserção no mundo do trabalho para o fato do indivíduo não se adequar às exigências de qualificação que são postas pelo novo paradigma de produção. É como se existisse oferta de emprego para toda a população economicamente ativa, cabendo ao trabalhador adaptar-se às exigências das demandas de postos laborais. Isto é, nessa perspectiva, faz-se crê que exista uma relação linear, latente, entre desenvolvimento econômico e desenvolvimento educacional que resultaria em um fortalecimento do setor produtivo.

Entretanto, conforme Sanchis (1997),

O crescimento econômico depende do desenvolvimento tecnológico que, por sua vez, exige maior nível de trabalho qualificado. Isto acontece porque com o desenvolvimento tecnológico reduz-se o número de postos de trabalho de baixo nível de qualificação, requalifica-se uma parte significativa dos empregos já existentes, aparecendo novos empregos mais qualificados. Daí se deduz a necessidade de se incrementar o percentual da população escolarizada, o que trará efeitos benéficos tanto para a sociedade quanto para os indivíduos. (1997, p. 210).

Contudo, no Brasil, com a educação básica de baixa qualidade, aliado a necessidade da população jovem mais empobrecida inserir-se no mundo do trabalho cada vez mais cedo, impossibilitando na maioria dos casos a continuidade na escola em direção a cursos superiores, restam-lhes as ofertas de cursos de qualificação profissional aligeirado e desprovidos de conteúdos em formar humanos integrais. Para essa camada populacional, alvo central dos Planos de qualificação em massa ou os oferecidos pela iniciativa privada, conduzidos e influenciados por essa ideologia do discurso da empregabilidade, tem-se a ilusão, com essas qualificações, de consecução de emprego e/ou tornar-se empregável para as oportunidades que supostamente possa surgir.

A noção de "empregabilidade" ou o discurso que se faz em seu nome, reside sob a égide da teoria do capital Humano e emerge nesse contexto de ideário neoliberal, no Brasil, na gestão de Fernando Henrique Cardoso, na ocasião do lançamento do Plano Nacional de Qualificação do TrabalhadorPLANFOR. 
Segundo Oliveira (2005), "esse conceito foi lançado por especialistas em outplacement $t^{\prime 4}$. Para o autor, essa noção de origem inglesa representa, na área de recursos humanos, um serviço prestado por especialistas às empresas, com o objetivo de um melhor encaminhamento ao processo de dispensas de profissionais de nível superior que ocupavam cargos executivos. Não obstante, passou também a contribuir no assessoramento desses profissionais visando facilitar sua recolocação no mercado de trabalho.

Em que pese o conceito ter como origem os profissionais mais graduados, passou a ser usado demasiadamente ao fazer referências à população com menor nível de escolarização e qualificação, com menor capacidade de "disputa" por uma vaga no chamado mercado de trabalho. Dessa maneira, para Oliveira (2008),

O conceito de 'empregabilidade' surgiu como instrumento de relativização da crise do emprego, face a incapacidade do setor produtivo de incorporar ou manter, no seu interior, o mesmo número de trabalhadores. Surgiu como justificativa para o desemprego em massa, atribuindo à má qualificação dos trabalhadores a culpa por estes não atenderem as novas exigências do mercado de trabalho. Nesse cenário, torna-se importante entender como o conceito de 'empregabilidade' passou a se relacionar diretamente com as atividades de qualificação profissional e de valorização da educação básica. (OLIVEIRA, 2008, p. 198. Grifos do autor).

Como dito acima, acerca da teoria do capital Humano, o discurso da empregabilidade, não difere ideologicamente dos objetivos implícitos daquele. Neste, também funciona como um mecanismo que retira do Estado e do capital a responsabilidade pela implantação de medidas capazes de garantir um mínimo de condições de sobrevivência para a população.

Para o referido autor, no sentido mais comum do termo, empregabilidade tem sido entendida como a capacidade de o indivíduo manter-se ou reinserir-se no chamado mercado de trabalho, indicando a necessidade de este agrupar-se a um conjunto de ingredientes que o torne capaz de competir com todos aqueles demais desempregados que disputam e lutam por um determinado emprego. (OLIVEIRA, 2008).

Para Alves (2007), acerca do discurso da empregabilidade,

ele traduz as exigências de qualificações, mas incorpora em si, como contrabando ideológico, a promessa obliterada da possibilidade concreta de inclusão social no sistema orgânico

\footnotetext{
${ }^{4}$ Mais conhecido como transição de carreira, é uma significativa ferramenta de gestão organizacional que tem como finalidade apoiar e orientar colaboradores que foram desligados de uma empresa rumo a uma futura recolocação profissional. Disponível em: http://www.jrmcoaching.com.br/blog/o-que-significa-outplacement-e-qual-o-seu-conceito/.
} 
do capital. O discurso da empregabilidade oculta à natureza íntima do desenvolvimento tardio do capital, ou seja, a lógica da produção destrutiva e da exclusão social. (ALVES, 2007.p.250. Grifos do autor).

Sendo assim, para o autor, o conceito de empregabilidade é um dos conceitos significativos da lógica do Toyotismo e consiste no escopo ideológico das políticas de formação profissional. "Atualmente, tornou-se senso comum nas ideologias de qualificação profissional no capitalismo Global". (ALVES, p. 251).

Para esse autor, o conceito opera com transparência ideológica as contradições da mundialização do capital, um sistema mundial de produção de mercadorias, com foco na lógica da financeirização e da "produção enxuta", fatores que são totalmente contrários às políticas de pleno emprego e geradora de desemprego e, por conseguinte, exclusão social. Por isso, é que a mundialização do capital tende a disseminar, como fundamentação central de sua política de qualificação profissional, o conceito de empregabilidade, que aparece nos discursos de neoliberais e sociais democratas, aqui no Brasil. (ALVES, 2007).

Como exemplos dessa centralidade do discurso ideológico da empregabilidade, utilizou-se com relativo consenso, como condição básica para a superação da crise do desemprego, políticas de qualificação em massa de trabalhadores/as nos governos de Fernando Henrique Cardoso, na ocasião da implantação do PLANFOR, no governo Lula da Silva em 2003 com o PNQ e no de Dilma Rousseff, com o lançamento do PRONATEC em 2011, respectivamente.

O autor completa o raciocínio, ancorado em Forrester (1991), que essa ideologia é demasiada irônica, para não dizer trágico que,

Um sistema mundial de produção de mercadorias que aboliu a sua capacidade de integrar todos à vida produtiva e que torna cada vez mais explícito o seu caráter de produção destrutiva, procure legitimar suas políticas de administração da crise social no mundo do trabalho através do conceito que supõe ainda a capacidade de ser "empregável" num mundo caracterizado pelo "horror econômico" (FORRESTER, 1991, apud, Alves, 2007, p. 251. Grifos do autor).

Corroborando sobre a gênese do conceito de Empregabilidade no Brasil, Para Silva (2015),

este foi altamente difundido no PLANFOR, implementado de 1996 a 2002, por ocasião do governo de FHC." Reforça ainda que [...] "no contexto do Planfor, a empregabilidade era entendida como a capacidade individual de obtenção de 
emprego ou de desenvolvimento de alternativas de geração e elevação de renda". (SILVA, 2015, p. 125-126. Grifos do autor).

Como se observa, enviesado pela ideologia da Empregabilidade, no PLANFOR, o discurso da necessidade de se qualificar para se tornar competitivo no mercado, esteve subjacente a essa política pública.

Ainda de acordo com Silva (2015), na época da vigência do PLANFOR era muito forte o modelo da "pedagogia das competências", e que no contexto do PRONATEC, a autora avaliou que ideologicamente esse discurso é retomado com a intenção principal de legitimação do modo de produção do capital, mormente, com os cursos de curta duração do PRONATEC-FIC.

\section{RESULTADOS E DISCUSSÕES}

Nas definições de empregabilidade apresentadas, essa noção é vista como a capacidade de adaptação da mão-de-obra frente às novas exigências do mundo do trabalho e das organizações. No entanto, não há um consenso em relação a isso. Um dos questionamentos pertinentes à utilização da noção é decorrente do fato de as possibilidades de inserção no mundo do trabalho, apesar de estarem relacionadas fortemente com o capital cultural do trabalhador/a, não se resumirem a uma avaliação de suas competências necessária à ocupação de um posto de trabalho.

Para Oliveira (2008), o momento atual de desenvolvimento do capitalismo, estrutura-se por uma dinâmica de eliminação de postos de trabalho, o que denota uma busca do capital de tornar-se autônomo em relação à força de trabalho.

Diante do exposto, infere-se que a nova lógica da mundialização do capital significa não ao abandono e o distanciamento da precursora teoria do capital humano, que se disseminou na "época de ouro" do capitalismo, no final do século passado. Porquanto, sua concepção individualista se adequa à hegemonia neoliberal, porém, tendo na empregabilidade, uma nova versão dessa teoria.

É, portanto, a noção de "Empregabilidade" que irá apresentar essa nova tradução dessa teoria sob o capitalismo global: a educação ou aquisição (consumo) de novos saberes, competências e credenciais apenas habilitam os trabalhadores/as para competirem em um mercado de trabalho cada vez menor, não garantindo, portanto, com a mera posse de novas qualificações, a inserção do indivíduo a um emprego no mundo do trabalho. (ALVES, 2007)

Todavia, o que a grande mídia corporativa, a serviço principalmente do grande capital, salienta a exaustão, é a necessidade de os indivíduos "consumirem" novas competências, saberes e habilidades por meio de cursos de Qualificação Profissional como ocorreu nas políticas públicas de 
qualificação profissional em massa de trabalhadores/as brasileiros/as, no Plano Nacional de Qualificação do Trabalhador - PLANFOR, na década de 90 do século passado; no Plano Nacional de Qualificação - PNQ, no início dos anos 2000 e no PRONATEC, em 2011, como exemplos. (FONSECA, 2019)

Dessa maneira, tratado como uma mercadoria qualquer, a força midiática dá a sua colaboração maciça, por meio da propaganda veiculada nos diversos meios de comunicação, principalmente 0 televiso e internet, reforçando o chamamento para esse fim. E, na esteira dessa ideologia por meio do discurso falacioso da "empregabilidade", com o apoio inconteste da grande mídia, emergem também no mercado, tanto no nível básico, como também no superior, por meio das parcerias pública-privado e na iniciativa privada, oportunidades de negócios rentáveis. Várias empresas do ramo, inclusive muitas franquias especializadas no negócio de formação/qualificação profissional para o trabalho, direcionam-se a quem só tem o ensino básico, com a maioria dos cursos destinados a quem só tem o ensino fundamental incompleto ou completo.

Com relação aos cursos FIC, essa ideologia da empregabilidade, destina-se, principalmente, às pessoas que historicamente não tiveram oportunidades de uma educação básica e propedêutica de qualidade para que pudessem seguir ou escolher ir até o nível superior de ensino ou tiveram que largar a educação básica para trabalharem precocemente visando a auxiliar no autossustento ou de sua família. Embora, haja um crescente número de pessoas com diploma de graduação e de pós-graduação trabalhando em áreas adversas de sua formação ou na informalidade, o grupo mais visado dessa ideologia, portanto, são os mais vulneráveis socioeconomicamente.

A essas pessoas são ofertados cursos em larga escala pela iniciativa privada, ou em programas governamentais de supostas qualificações em massa, em variados segmentos profissionais, como uma falsa promessa de inserção ou de recolocação no chamado mercado de trabalho. No campo do privado, por sua vez, materializase a dinamização do mercado de qualificação profissional, com ofertas de variados tipos de cursos, destinados a quem puder pagar por essa suposta qualificação.

Ademais, seguindo essa lógica, a operacionalização ideológica de forma sutil e quase imperceptível de atribuir aos indivíduos, somente a eles, a "culpa" pelo seu fracasso na vida profissional ou de não inserção no mundo do trabalho, a força ideológica do capitalismo neoliberal tem o poder de pôr a culpa nas vítimas por estarem desempregados ou desocupados. Ou seja, recai sobre os próprios sujeitos individualmente a culpa do seu sucesso ou fracasso em sua vida laboral, isentando o Estado de suas responsabilidades sociais.

Entretanto, o sistema vigente de ideário neoliberal, cujas características, notadamente, concentrador de renda, produtor de desigualdades sociais e de 
desemprego estrutural e que reflete negativamente no campo educacional, onde se mantem a dualidade educacional, que prima por teimar em oferecer uma educação pobre para os pobres, em detrimento de uma formação humana em que possibilite aos sujeitos à compreensão dos princípios e fundamentos subjacentes as atividades produtivas. Esse sistema, portanto, é o principal responsável por mazelas sociais que fazem parte do cotidiano do brasileiro/a.

Além disso, qualquer área de conhecimento necessita de base e compreensão dos fundamentos para se aprender uma profissão. Um indivíduo que não teve uma educação básica de qualidade, laica, pública e universal, dificilmente conseguirá inserção no mundo do trabalho com cursos aligeirados, esporádicos e fora de sintonia com as demandas reais do mercado da força de trabalho.

\section{CONSIDERAÇOES FINAIS}

Resta claro, portanto, que a noção de "empregabilidade" que se fundou na teoria do capital humano, esvazia a concepção de um movimento integrador e de responsabilidade coletiva. Não por acaso sua assunção torna-se claro em um cenário de desresponsabilização do Estado com as políticas sociais, por outro lado, a minimização de sua atuação regulatória das relações entre capital e trabalho. (OLIVEIRA, 2008).

A noção de empregabilidade, portanto, é a face moderna da teoria do capital humano. Ambas, portanto, se apresentam em períodos históricos distintos, porém, com uma mesma ideologia: a educação e a qualificação profissional garantidora de inserção e/ou permanência no mundo do trabalho, todavia, descoladas da outras dimensões sócio politicas e econômicas geradoras de empregos e rendas para a classe trabalhadora.

\section{REFERÊNCIAS}

ANTUNES, R. Adeus ao trabalho ? Ensaio sobre as metamorfoses e a Centralidade do Mundo do Trabalho.1997, 4a ed., São Paulo: Cortez.

ALVES, Giovanni. Dimensões da restruturação produtiva. Ensaio de Sociologia do Trabalho. $2^{\circ}$ ed. Editora Práxis. 2007.

CHAUÍ, Marilena de Souza. O que é ideologia. $17^{\circ}$ ed. São Paulo. Ed. Brasiliense, 1980.

FERREIRA, E. B. A Educação Profissional no Planejamento Plurianual do Governo FHC. Tese (Doutorado) - Universidade Federal de Minas Gerais, Faculdade de Educação, Belo Horizonte, 2006. 
FONSECA, Janilson Gomes da. O plano de qualificação do trabalhador e a noção deempregabilidade nas políticas de capacitação para o trabalho a partir de 1990. 2019. 141f. Dissertação (Mestrado em educação profissional). Instituto Federal de Educação, Ciência e Tecnologia do Rio Grande do Norte. Natal, 2019.

FRIGOTTO.G; CIAVATTA.M; RAMOS.M. Educação como capital humano: uma teoria mantenedora do senso comum. In: a produtividade da escola improdutiva. São Paulo. Cortez. 4.ed.1993 (p. 35 - 68).

FRIGOTTO, Gaudêncio, A produtividade da Escola Improdutiva. 7 ed. São Paulo: Editora Cortez, 2006.

GUERRA, Maria do Carmo Bueno. Empregabilidade. Dicionário de políticas públicas. CASTRO, L.F; CONTIJO, C.R.B; AMABILE, A.E.N. (orgs) UFMG. 2012

HARVEY, David. A Condição Pós-moderna. São Paulo. Loyola. 1993. ( p. 117-134. Cap. 6, 7 e 8).

KUENZER, Acácia. Ensino de 2grau: 0 trabalho como princípio educativo. 3ed"a. São Paulo: Cortez, 1997.

MARX, Karl e ENGELS, F. A ideologia Alemã . $6^{\circ}$ ed. São Paulo. Ed. HucitecSão Paulo,1987.

OLIVEIRA, Ramon de. Empregabilidade. In: Dicionário de Educação Profissional em Saúde. PEREIRA, I. B; LIMA, J.C.F. ( ORG.). $2^{\circ}$ Ed. Ver. Ampl. - Rio de Janeiro : EPSJV, 2008. 478 p.

SANCHIS, Enric. Da Escola ao Desemprego. Agir, São Paulo: 1997.

SCHULTZ, T.O Capital Humano: Investimento em educação e pesquisa. Trad. De Marco Aurélio de M. Matos. Rio de Janeiro. Zarhar,1973. p.31-52.

SILVA, Danilma de Medeiros. Desvelando o Pronatec: uma avaliação política do programa. Dissertação de Mestrado em Educação. Universidade Federal do Rio Grande do Norte. Natal-RN. 2015. 